\title{
Identification of proteins in activated human neutrophils susceptible to tyrosyl radical attack. A proteomic study using a tyrosylating fluorophore
}

\author{
Diana Avram ${ }^{1}$, Edwin P. Romijn ${ }^{2}$, Everard H. W. Pap ${ }^{1 *}$, Albert J. R. Heck ${ }^{2}$ and \\ Karel W. A. Wirtz ${ }^{1}$ \\ ${ }^{1}$ Department of Biochemistry of Lipids, Center for Biomembranes and Lipid Enzymology, \\ Institute of Biomembranes \\ ${ }^{2}$ Department of Biomolecular Mass Spectrometry, Bijvoet Center and Utrecht Institute for \\ Pharmaceutical Sciences, Utrecht University, Utrecht, The Netherlands
}

Tyrosyl radicals cross-linked to protein tyrosine residues (tyrosylated proteins) represent hallmarks of neutrophil-mediated injury at the inflammatory locus. Yet the proteins targeted by tyrosyl radicals in an intact cellular system remain to be elucidated. Here, we show that tyrosyl radicals generated by human neutrophils after activation by phorbol 12-myristate 13-acetate (PMA), interferon- $\gamma$ (IFN- $\gamma$ ) or TNF- $\alpha$ could act in an autocrine manner by cross-linking to endogenous proteins. We have identified the tyrosylated proteins by using a membraneimpermeable tyrosine analogue, tyramine coupled to fluorescein (TyrFluo), in combination with proteomics techniques. Confocal microscopy images indicated that initially the tyrosylated proteins were localized in patches at the cell surface to become internalized subsequently. In the neutrophil membrane-associated proteome, lactoferrin was the prime target of tyrosylation. Out of three isoforms identified, an $80 \mathrm{kDa}$ neutral isoform was tyrosylated more extensively than the $85 \mathrm{kD}$ basic isoform, particularly after PMA activation. Although all three stimuli induced tyrosylation of the filamentous component vimentin, additional tyrosylated vimentin fragments were detected after IFN- $\gamma$ - and TNF- $\alpha$-stimulation. Moreover, upon activation the bulk of vimentin behaved as a dimer $\left(M_{\mathrm{r}} 120 \mathrm{kDa}\right)$ being slightly tyrosylated, yet phosphorylated at Thr-425 possibly as a requirement for its externalization. Unexpectedly, bovine catalase added to end tyrosyl radicals formation was detected as a highly tyrosylated neutrophil-associated protein. A moderate stimulus-dependent tyrosylation of ATP synthase$\beta, \alpha$-enolase, glyceraldehyde 3-phosphate dehydrogenase, cytokeratin-10, filamin-A, and annexin-I was also observed. When the membrane-permeable probe (acetylTyrFluo) was used, protein tyrosylation was not observed indicating that the intracellular proteins were well protected against oxidative attack. This study shows that human neutrophils can modulate their proteome via a tyrosine oxidation pathway induced by pro-inflammatory mediators.

Keywords: Neutrophil proteome / Pro-inflammatory cytokines / Tyrosylated proteins / Tyrosyl radicals

\begin{tabular}{|lr|}
\hline Received & $23 / 9 / 03$ \\
Revised & $16 / 12 / 03$ \\
Accepted & $29 / 1 / 04$ \\
\hline
\end{tabular}

Correspondence: Dr. Diana Avram, Department of Biochemistry of Lipids, Institute of Biomembranes, Utrecht University, Padualaan 8, $3584 \mathrm{CH}$ Utrecht, The Netherlands

E-mail: d.avram@chem.uu.nl

Fax: +31-30-2533151

Abbreviations: acetylTyrFluo, acetylated form of TyrFluo; fMLP, $\mathrm{N}$-formyl-methionyl-leucyl-phenylalanine; HBSS, Hank's balanced salt solution; IFN, interferon- $\gamma$; MPO, myeloperoxidase; PKC, protein kinase C; PMA, phorbol 12-myristate 13-acetate; TNF- $\alpha$, tumor necrosis factor- $\alpha$; TyrFluo, tyramine linked to 6-(fluorescein-5-(and-6)-carboxamido) hexanoic acid

\section{Introduction}

Polymorphonuclear neutrophils (PMNs) play an essential role in the host defense against invading microorganisms. An imperative step during the inflammatory response involves NADPH activation to generate superoxide anion $\left(\mathrm{O}_{2}^{-}\right)$which undergoes rapid dismutation to hydrogen

\footnotetext{
* Current address: Aventis Pharma AG, Drug Innovation \& Approval/HTS, Industriepark Hoechst Bldg H811, D-65926 Frankfurt am Main, Germany
} 
peroxide $\left(\mathrm{H}_{2} \mathrm{O}_{2}\right)$ [1]. The release of reactive oxygen intermediates during the oxidative burst is accompanied by the exocytosis of myeloperoxidase (MPO) from the azurophilic granules. The MPO- $\mathrm{H}_{2} \mathrm{O}_{2}$ oxidative system generates highly toxic agents such as hypochlorous acid $(\mathrm{HOCl})$ that in turn can cause extensive tissue injury [2, 3]. Provided free iron is present, $\mathrm{O}_{2}^{-}$and $\mathrm{H}_{2} \mathrm{O}_{2}$ may react in an iron-catalyzed reaction to yield the hydroxyl radical $(\mathrm{OH})$ which can cause extensive oxidative damage of microorganisms and host tissues [4]. Moreover, $\mathrm{O}_{2}{ }^{-}$may react with nitric oxide (NO) to form peroxynitrite which could mediate the nitration of protein tyrosine residues causing profound downstream effects on the functionality of essential enzymes and cellular receptors [5-7].

An increasing body of evidence has shown that MPO$\mathrm{H}_{2} \mathrm{O}_{2}$ may convert free L-tyrosine in human blood plasma via an one-electron oxidation reaction to the tyrosyl radical [8-10]. By reacting with tyrosine residues of target proteins the tyrosyl radical may produce $0,0^{\prime}$-dityrosine bonds. Proteins may also be oxidized by $\mathrm{HOCl}$ producing chlorotyrosine and to a lesser extent dityrosine [11, 12]. In addition, low levels of peroxynitrite could also give rise to dityrosine formation [13]. Association of tissue dysfunction with elevated levels of tyrosyl radicals or their ensuing products has become evident in diseases such as atherosclerosis, carcinogenesis, Parkinson's disease and ischemia/reperfusion injury [14].

Potential markers for tyrosyl radical-mediated oxidation, such as dityrosine, nitrotyrosine, and chlorotyrosine, have been detected in model proteins or lipoproteins [12, 15]. Recently, we have shown that phorbol ester-activated neutrophils oxidatively modify proteins in endothelial cells in culture [16]. In the latter study we made use of the tyramine-fluorescein conjugate (TyrFluo) that upon oxidative burst is converted into tyrosyl radicals and may couple to tyrosine residues of proteins. A similar fluorescent conjugate was coupled to extracellular matrix proteins of human lung fibroblasts upon activation by transforming growth factor- $\beta 1$ in the presence of horseradish peroxidase [17]. So far, there are very few studies that deal with the neutrophil-dependent oxidation of cellular proteins under physiological conditions. Recently, mouse peritoneal neutrophils activated in vivo were found to increase their content of protein-bound dityrosine [18]. Levels of $0,0^{\prime}$-dityrosine in urine mirrored those in neutrophil proteins.

Here, we show that activation of neutrophils by phorbol 12-myristate 13-acetate (PMA), tumor necrosis factor- $\alpha$ (TNF- $\alpha$ ), and interferon- $\gamma$ (IFN- $\gamma$ ) in the presence of TyrFluo leads to the tyrosylation of a number of endogenous proteins. Maps of soluble and membrane-associated proteins were made by two-dimensional gel electrophoresis.
By matching the tyrosylated proteins visualized by Western blotting with the protein maps, spots of the corresponding silver-stained gels were selected and analyzed by mass spectrometry (MS) to identify the proteins susceptible to tyrosyl radical attack. Although there is a great interest in the relationship between protein function and signaling in neutrophils as mediated by radicals generated during an acute inflammatory process, a global pattern of endogenous oxidatively modified proteins has not been documented to date. Here we present evidence that neutrophil proteins with anti-inflammatory and bactericidal properties are the most susceptible to tyrosyl radical attack.

\section{Materials and methods}

\subsection{Isolation of neutrophils}

Heparinizied venous blood obtained from the blood bank of the Utrecht Medical Center, Utrecht University, was diluted with one volume of RPMI 1640 and centrifuged on discontinuous Ficoll-Paque gradient (Pharmacia, Uppsala, Sweden). Red cells contaminating neutrophils in the bottom layer were lysed with $15 \mathrm{vol}$ of $0.15 \mathrm{M}$ ammonium chloride solution for $30 \mathrm{~min}$ at $4^{\circ} \mathrm{C}$ [19]. After washing three times in ice-cold $\mathrm{HBSS}^{-}\left(\mathrm{Ca}^{2+}-, \mathrm{Mg}^{2+}-\right.$, and phenol red-free Hank's balanced salt solution, $\mathrm{pH} 7.4$, containing $1 \mathrm{mg} / \mathrm{mL}$ glucose) neutrophils were resuspended to $10^{7} / \mathrm{mL}$ cells in the same buffer. Cell viability was $>98 \%$ as determined by trypan blue exclusion test. All procedures were conducted in the absence of divalent cations to prevent cell aggregation or activation and under sterile condition to avoid endotoxin contamination.

\subsection{Fluorimetric detection of extracellular dityrosine formation}

Neutrophils $\left(3 \times 10^{6}\right.$ cells) diluted in $2 \mathrm{~mL}$ prewarmed HBSS $^{-}$were incubated with $1 \mathrm{~mm}$ tyramine in a standard cuvette at $37^{\circ} \mathrm{C}$ using a spectrofluorometer (Photon Technology International, Lawrenceville, NJ, USA) equipped with a thermostatted cuvette holder and a magnetic stirring device. Neutrophil activation was induced by the addition of $1 \mu \mathrm{g} / \mathrm{mL}$ PMA (Sigma, St. Louis, MO, USA), $0.6 \mathrm{ng} / \mathrm{mL}$ TNF- $\alpha$ (BioSource, Camarrilo, CA, USA), $0.6 \mathrm{ng} / \mathrm{mL}$ IFN- $\gamma$ (BioSource) or $1 \mu \mathrm{M} N$-formyl-methionylleucyl-phenylalanine (fMLP) (Sigma) to the cell suspension in the cuvette. Dityrosine (dityramine) formation in the medium was measured continuously up to 20-40 min at excitation and emission wavelenghts of $325 \mathrm{~nm}$ and $405 \mathrm{~nm}$, respectively [10]. Data were collected and analyzed using Microsoft Excel software. 


\subsection{Tyrosylation of neutrophil proteins}

To investigate whether extracellular tyrosyl radicals generated by activated neutrophils could cross-link to endogenous proteins the membrane-impermeable tyramine-fluorescein conjugate (TyrFluo) was used [16, 20]. Neutrophils $\left(4 \times 10^{6}\right)$ in $0.4 \mathrm{~mL} \mathrm{HBSS}^{-}$were activated with PMA $(1 \mu \mathrm{g} /$ $\mathrm{mL})$ in the presence of TyrFluo $(5 \mu \mathrm{M})$ at $37^{\circ} \mathrm{C}$ under gentle agitation for $20 \mathrm{~min}$. When neutrophils were stimulated with TNF- $\alpha(0.6 \mathrm{ng} / \mathrm{mL})$ or IFN- $\gamma(0.6 \mathrm{ng} / \mathrm{mL})$, TyrFluo $(5 \mu \mathrm{M})$ was added after 15-20 min at which time tyrosyl radical formation began (see Section 3). TyrFluo labeling was carried out for an additional $45 \mathrm{~min}$. Under all conditions of stimulation the tyrosylation reaction was stopped by the addition of $100 \mu \mathrm{m}$ butylated hydroxytoluene (BHT) or $100 \mathrm{U} / \mathrm{mL}$ bovine catalase and by putting the cells on ice. Cells were then centrifuged at $1400 \mathrm{rpm}$ for $10 \mathrm{~min}$ at $4^{\circ} \mathrm{C}$ and washed three times in ice-cold $\mathrm{HBSS}^{-}$buffer. As a control nonstimulated neutrophils were used. To assess if the activation of neutrophils can lead to the tyrosylation of intracellular proteins, the membrane-permeable conjugate, acetylated at the fluorescein moiety (acetylTyrFluo) was used [20]. In this set of experiments, the neutrophils $\left(4 \times 10^{6}\right)$ were first incubated with the probe $(5 \mu \mathrm{m})$ for $15 \mathrm{~min}$ at $37^{\circ} \mathrm{C}$, washed twice, and then activated with PMA and lysed as described below. All experiments were performed in triplicate or quadruplicate.

\subsection{Extraction of cytosolic and membrane-associated proteins}

After labeling soluble and membrane-associated proteins were isolated from neutrophils using a modified method [21]. Briefly, the cells maintained on ice were lysed in sterile Milli-Q water $(0.1 \mathrm{~mL})$ supplemented with $1 \mathrm{~mm}$ PMSF, $1 \mathrm{~mm}$ EGTA, $2 \mu \mathrm{g} / \mathrm{mL}$ leupeptin, and $1 \mu \mathrm{g} / \mathrm{mL}$ pepstatin for $20 \mathrm{~min}$ at $4{ }^{\circ} \mathrm{C}$, with occasional vortexing. To complete the lysis the cells were frozen for an additional 30 min or kept overnight at $-40^{\circ} \mathrm{C}$. The lysates were centrifuged at $18000 \times g$ for $20 \mathrm{~min}$ at $4^{\circ} \mathrm{C}$ and the supernatants containing the cytosolic proteins were lyophilized and stored at $-40^{\circ} \mathrm{C}$ until use. The pellet containing the membrane-associated proteins was washed once in the lysis solution and the supernatant discarded. Proteins were extracted in RIPA buffer (1\% NP40, 150 mм NaCl, 1 mм PMSF, 1 mм EGTA, $2 \mu \mathrm{g} / \mathrm{mL}$ leupeptin, $1 \mu \mathrm{g} / \mathrm{mL}$ pepstatin, $40 \mathrm{~mm}$ Tris- $\mathrm{HCl}, \mathrm{pH}$ 7.4) to be analyzed by SDS-PAGE or lyophilized and stored at $-40^{\circ} \mathrm{C}$ to be analyzed by $2-\mathrm{D}$ PAGE (see Section 2.6).

\subsection{SDS-PAGE and immunoblotting}

The pellets containing the membrane-associated proteins were solubilized in RIPA buffer on ice for 30 min by vortexing at $4-5 \mathrm{~min}$ intervals. After centrifugation at $18000 \times g$ for 20 min at $4^{\circ} \mathrm{C}$, the supernatant containing the membrane-associated proteins was mixed with $4 \times$ denaturating buffer (100 mm Tris-HCl, pH 7.4, 100 mm DTT, 2\% SDS, $20 \% \mathrm{v} / \mathrm{v}$ glycerol, $0.025 \% \mathrm{w} / \mathrm{v}$ bromophenol blue) heated for $10 \mathrm{~min}$ at $95^{\circ} \mathrm{C}$, and separated on $10 \%$ SDS-PAGE. The cytosolic protein fractions were treated in the same way. The proteins were transferred on nitrocellulose membranes. The blots were blocked overnight at $4^{\circ} \mathrm{C}$ in TBS/ $0.05 \%$ Tween (Bio-Rad, Hercules, CA, USA) supplemented with $2 \%$ non-fat milk. Fluorescent tyrosylated proteins were detected by incubating the blots for $1 \mathrm{~h}$ at room temperature using an horseradish peroxidase (HRP)-conjugated antibody against fluorescein (Biogenesis, Poole, UK) diluted 1:800 in the blocking buffer. Tyrosylated proteins were visualized using the enhanced chemiluminescent detection system (Amersham).

\subsection{Two-dimensional gel electrophoresis}

The lyophilized soluble proteins and membrane-associated proteins obtained from $8-10 \times 10^{6}$ cells were solubilized in buffer $A(0.1 \mathrm{~mL})$ containing $8 \mathrm{M}$ urea, $0.5 \mathrm{M}$ thiourea, $\%$ CHAPS, 40 mм DTT, 1\% Triton-X 100, 40 mm Tris$\mathrm{HCl}, \mathrm{pH} 7.6$, and $0.5 \%$ Bio-Lytes 3-10 supplemented with $5 \mathrm{~mm}$ PMSF. The samples were vortexed and sonicated in an ice-water bath at $10 \mathrm{~min}$ intervals for $30 \mathrm{~min}$ and centrifuged at $18000 \times g$ for $20 \mathrm{~min}$ at $16^{\circ} \mathrm{C}$. Supernatants were mixed with one volume of buffer $A$ (without PMSF). The proteins were submitted to 2-D PAGE according to the manufacturer's instruction (Bio-Rad). Briefly the IPG strips $(11 \mathrm{~cm}, \mathrm{pH} 3-10$ or 4-7) were rehydrated in buffer containing samples for 2-3 h under passive conditions followed by active rehydratation at $50 \mathrm{~V}$ for 9-10 h. IEF was carried out in a PROTEAN ${ }^{\circledR}$ IEF cell (Bio-Rad) in three steps, 15 min at $250 \mathrm{~V}, 2.5 \mathrm{~h}$ up to $5000 \mathrm{~V}$, then $5500-6500 \mathrm{~V}$ until a total of $45000 \mathrm{Vh}$ was reached. In some instances, IPG strips of $17 \mathrm{~cm}(\mathrm{pH} 3-10)$ were used to improve the resolution of proteins present at low levels. Protein separation in the second dimension was performed on a $15 \%$ or $12.5 \%$ SDS acrylamide gel according to Celis [22]. Each sample was analyzed in duplicate; one gel was silver-stained and the other gel was used for detection of tyrosylated proteins by Western blotting. Upon matching the silver-stained tyrosylated proteins were cut out and used for mass spectrometric analysis.

\subsection{Mass spectrometric analysis of protein spots}

\subsubsection{Protein digestion}

The silver-stained spots of interest were first washed with water and then destained with $30 \mathrm{mM} \mathrm{K}_{3} \mathrm{Fe}(\mathrm{CN})_{6}, 100 \mathrm{~mm}$ $\mathrm{Na}_{2} \mathrm{~S}_{2} \mathrm{O}_{3}$. Gel slices were washed twice by dehydration 
with $\mathrm{ACN}$ and rehydration by $50 \mathrm{~mm} \mathrm{NH}_{4} \mathrm{HCO}_{3}$. Next, gel slices were dried in a vacuum centrifuge and rehydrated

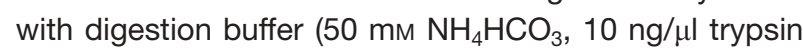
(Roche Diagnostics, Indianapolis, IN, USA; sequencing grade) at $4^{\circ} \mathrm{C}$. After $60 \mathrm{~min}$, supernatants were removed and replaced with 15-25 $\mu \mathrm{L}$ of $50 \mathrm{~mm} \mathrm{NH}_{4} \mathrm{HCO}_{3}$, to keep the gel pieces moist. Trypsin digestion was performed overnight at $37^{\circ} \mathrm{C}$ and the resulting peptide mixtures from in-gel digests were purified and concentrated using $\mu$ ZipTips C18 (Millipore, Bedford, MA, USA).

\subsubsection{Peptide mapping}

Peptides were subjected to mass spectrometric analysis by a slightly modified method [23, 24]. Tryptic peptides were eluted directly onto the MALDI target using $10 \mathrm{mg} /$ $\mathrm{mL} \alpha$-cyano-4-hydroxycinnamic acid (Fluka, Buchs, Switzerland) in ACN/ water (50/50) with 0.1\% TFA. Peptide mass fingerprints (PMFs) were acquired on a Voyager DE-STR (PerSeptive Biosystems, Framingham, MA, USA) reflectron TOF mass spectrometer. All MALDI spectra were internally calibrated using trypsin autolysis peptides.

\subsubsection{Nanoliquid chromatography-tandem MS (LC-MS/MS)}

In cases where an insufficient number of tryptic peptides were formed nano-LC was coupled to a Q-ToF (Micromass, Manchester, UK) mass spectrometer to identify protein spots. Nano-LC-MS/MS analysis was performed as described previously [25]. Peptide mixtures were delivered to the system using a Famos autosampler (LC Packings, Amsterdam, Netherlands) at $3 \mu \mathrm{L} / \mathrm{min}$, and trapped on an AquaTM C18 column ( $5 \mu \mathrm{m}$; Phenomenex, Torrance, CA, USA; column dimensions, $1 \mathrm{~cm} \times 100 \mu \mathrm{m}$ ID). After flow splitting down to $150-200 \mathrm{~nL} / \mathrm{min}$ peptides were transferred to the analytical column Pepmap ${ }^{\mathrm{TM}}$ (5 $\mu \mathrm{m}$; LC Packings; column dimensions, $25 \mathrm{~cm} \times 50 \mu \mathrm{m}$ ID) and separated in a gradient of ACN $(0.5 \%$ per min to $60 \%$ ). Fragmentation of the eluting peptides was performed in data-dependent mode.

\subsection{Protein identification}

ProteinLynx (Micromass, Manchester, UK) software was used to generate a single text file of a complete LC-MS/ MS experiment. This text file was used as input for the Mascot software that was used for database searches both for peptide mapping results and nano-LC-MS/MS results [26].

\subsection{Confocal laser scanning microscopy}

Neutrophils were labelled with TyrFluo or acetylTyrFluo as described above. Cells were washed three times with PBS and fixed with $4 \% \mathrm{w} / \mathrm{v}$ paraformaldehyde/0.1\% w/v Triton X-100 in PBS for $1 \mathrm{~h}$ at room temperature. After fixation, $50 \mathrm{~mm}$ ammonium chloride in PBS $(3 \times 5 \mathrm{~min})$ was added to neutralize the remaining paraformaldehyde. Images of fixed and nonfixed cells were taken with a Leica TCSNT confocal laser scanning system on an inverted microscope DMIRBE (Leica Microsystems) with an argon-krypton laser as excitation source ( $\lambda$ exc $488 \mathrm{~nm}$ ). Emission was detected using a 530/30 bandpass filter.

\section{Results}

\subsection{Tyrosyl radical formation by neutrophils activated by PMA, IFN- $\gamma$, and TNF- $\alpha$}

Tyramine as the biogenic analog of L-tyrosine was used to measure tyrosyl radical formation in the extracellular medium of activated neutrophils. Radical formation was followed in time by the continuous recording of the dimerization reaction, i.e., dityramine formation (Fig. 1). Neutrophil activation by PMA yielded dityramine after a lag time of three min whilst the dimerization reaction continued up to 20 min (curve 1). IFN- $\gamma$ and TNF- $\alpha$ known to prime the oxidative burst of neutrophils through receptor activation, also induced dityramine formation (curves 2, 3). However, upon addition of these cytokines the tyrosyl radical formation showed a delay of 15-20 min. In agreement with this, the association of TNF- $\alpha$ with its $55 \mathrm{kDa}$ receptor is known to proceed rather slowly $\left(t_{1 / 2 \text { (ass) }}=22 \mathrm{~min}\right.$ ) [27]. Activation of neutrophils by fMLP does not give rise to

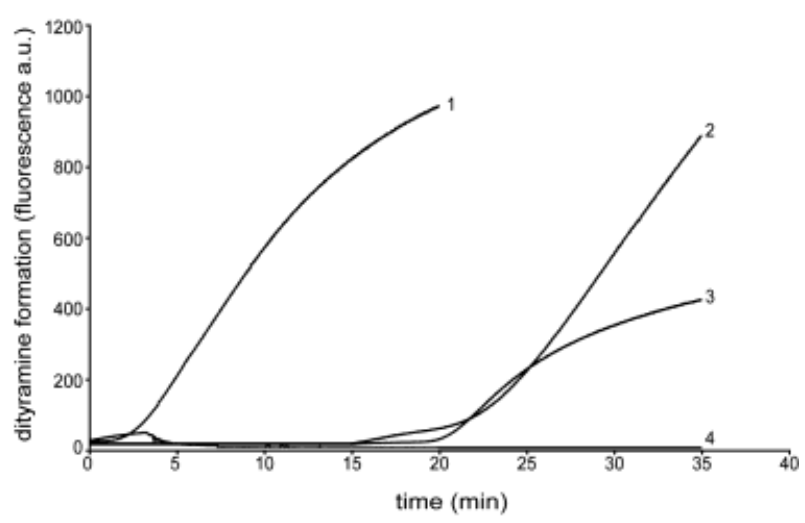

Figure 1. Dityramine formation by activated neutrophils. PMNs were activated by PMA (curve 1), IFN- $\gamma$ (curve 2), TNF- $\alpha$ (curve 3 ) in the presence of tyramine (1 mM) as described in Section 2; control (curve 4). Dityramine formation was followed in time by measuring its fluorescence $\left(\lambda_{\mathrm{ex}} 325 \mathrm{~nm} / \lambda_{\mathrm{em}} 405 \mathrm{~nm}\right)$. 
dityramine formation (data not shown). This agrees with previous observations that without priming of the neutrophils $\mathrm{fMLP}$ activation generated minimal amounts of $\mathrm{H}_{2} \mathrm{O}_{2}$ [28].

\subsection{Protein tyrosylation in PMA-activated neutrophils}

To establish whether the PMA-induced oxidative burst leads to the oxidation of the endogenous proteins, neutrophils were incubated with the membrane-impermeable TyrFluo conjugate $(5 \mu \mathrm{M})$. After PMA-activation, the neutrophil proteins were separated in a membrane-associated and soluble protein fraction. As shown in Fig. 2a, the membrane-associated proteins were extensively labeled (lane 6) whilst the labeling of soluble proteins was very limited (lane 2). Protein tyrosylation was completely inhibited by the protein kinase $C$ (PKC) inhibitor GF 109203X ( $2 \mu \mathrm{M}$ ) (data not shown). Labeling of both protein fractions was negligible in untreated neutrophils (lanes 1 and 5). The same experiments carried out with the membrane-permeable acetylTyrFluo conjugate showed that PMA-activation did not give rise to labeling of membrane-associated (lanes 7,8 ) or soluble proteins (lanes 3,4$)$. This indicates that activation did not generate tyrosyl radicals inside the cell to the extent that the probe was covalently coupled to intracellular proteins.

AcetylTyrFluo taken up by neutrophils is deacetylated by cytosolic esterases [29]. As shown by confocal laser scanning microscopy, the ensuing deacetylated TyrFluo product was present throughout the cells after PMA-stimulation (Fig. 2b). Subsequent permeabilization and fixation resulted in a complete release of the probe (Fig. 2c). This confirms that intracellular proteins are not tyrosylated in activated neutrophils. In contrast, PMA-activation (5 $\mathrm{min}$ ) in the presence of membrane-impermeable TyrFluo showed fluorescent patches at the plasma membrane or in close proximity (Fig. 2d). For an optimal visualization of these patches optical sections of fixed cells were taken after 15 min of PMA-activation (Fig. 2e). As one can see the bulk of fluorescence is present in relatively large intracellular compartments throughout the cell most likely reflecting the internalization of tyrosylated membrane proteins.

\subsection{Proteomic analysis based on Western blotting}

The maps of membrane-associated and soluble proteins (Figs. 3a, b) were obtained from TNF- $\alpha$-activated neutrophils. These maps are representative for the neutrophil proteome although some variations in protein levels can

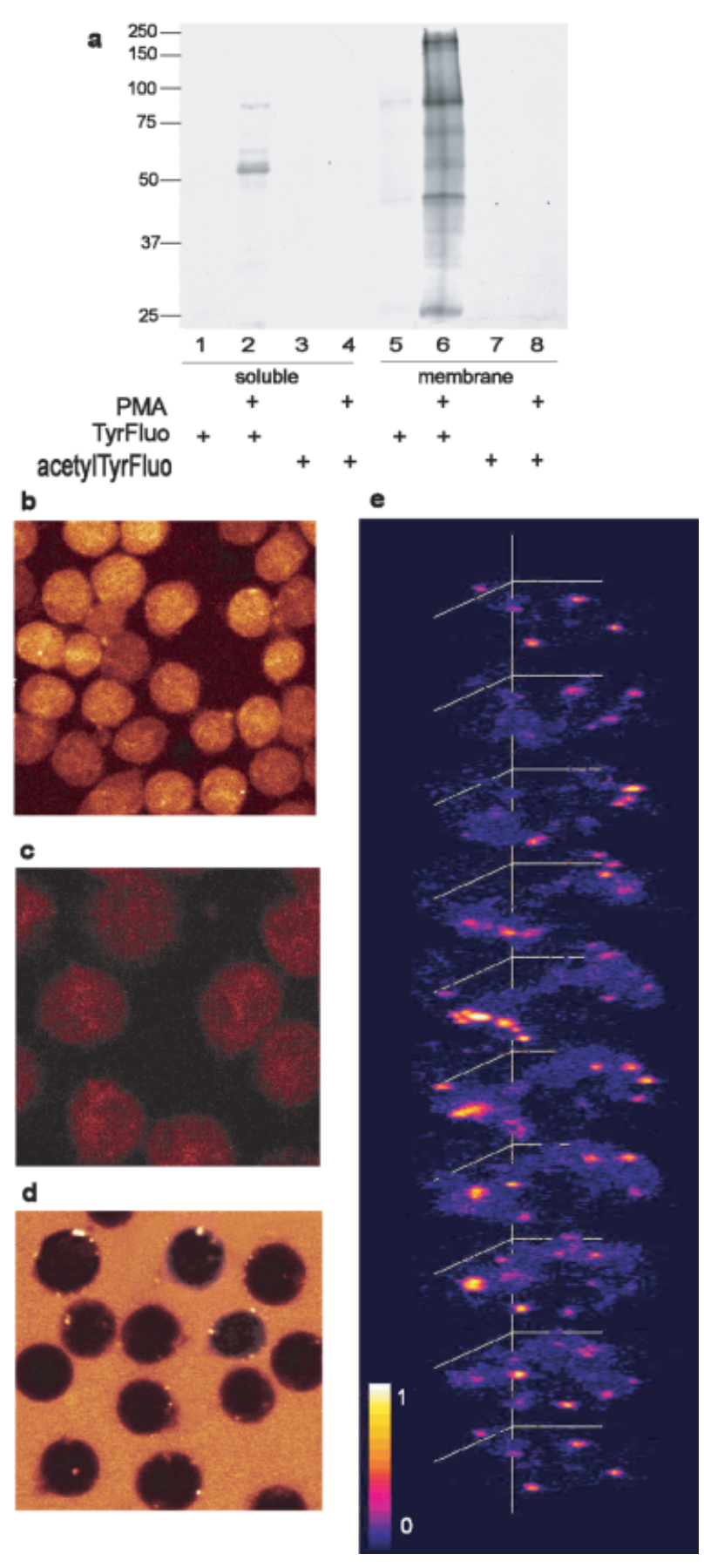

Figure 2. PMA activation of neutrophils induces the tyrosylation of membrane-associated proteins. (a) Western blots of soluble and membrane-associated proteins from PMNs incubated with membrane-impermeable TyrFluo (lanes 1, 2, 5, 6) and membrane-permeable acetylTyrFluo (lanes 3, 4, 7, 8); (b) confocal images of nonfixed PMNs loaded with acetyl TyrFluo, washed and stimulated for 15 min with PMA; (c) PMNs from (b) after permeabilization and fixation; (d) nonfixed PMNs in the presence of TyrFluo stimulated for 5 min with PMA; (e) confocal optical sections of a single fixed PMN after 20 min of stimulation with PMA in the presence of TyrFluo (1000-fold magnification). 


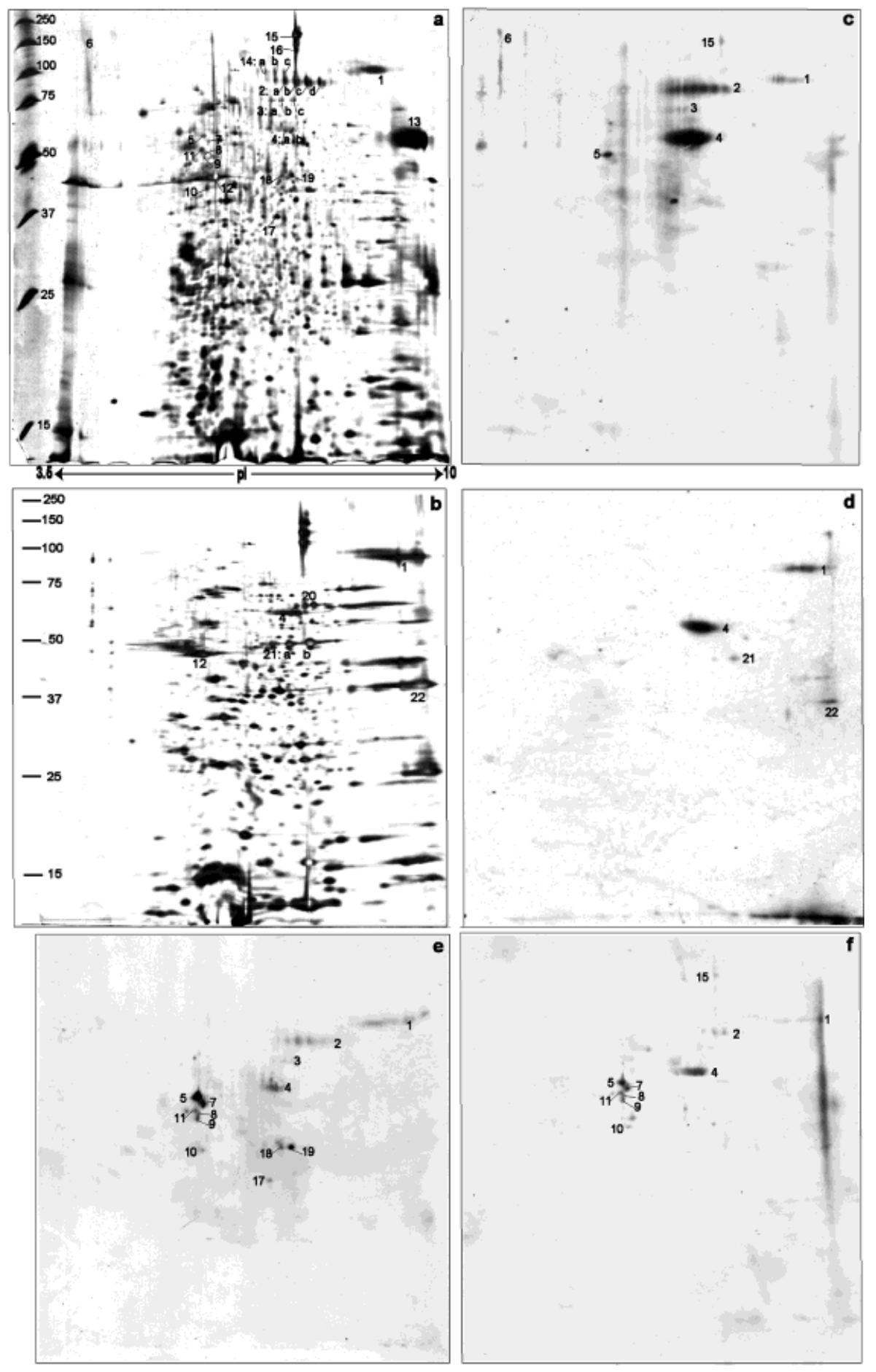

Figure 3. Two-dimensional maps of soluble and membrane-associated proteins from activated neutrophils and corresponding Western blots of tyrosylated proteins. Silver-stained 2-D gel of (a) membrane-associated proteins, (b) soluble proteins after TNF- $\alpha$ stimulation; tyrosylation pattern of (c) membrane-associated and (d) soluble proteins after PMA-stimulation and of membrane-associated proteins (e) after IFN- $\gamma$ and (f) TNF- $\alpha$ stimulation. Numbers indicate the proteins identified by MS. Prestained protein markers (Bio-Rad) run in parallel (left side of the master maps), isoelectric point $(\mathrm{p} /)$ range of $3.5-10$ is indicated on the horizontal axis (a). be observed depending on the stimulus used. Analysis by the PD-Quest software (Bio-Rad) estimated about 1200 spots for the membrane-associated proteins and about 600 spots for the cytosolic/soluble proteins. We have identified from the membrane-associated protein map (Fig. 3a) $\beta / \gamma$-actin (spot 12), myeloperoxidase (spot 13), and cytokeratin 10 (spot 16) and from the soluble protein map (Fig. 3b) $\beta / \gamma$-actin (spot 12) and catalase (spot 20). Some of these proteins were used as landmarks as their isoelectric points $(\mathrm{p} /)$ and molecular weights $\left(M_{\mathrm{r}}\right)$ agreed with the Swiss-Prot database (Table 1). We also identified a neutral isoform of lactoferrin, which was exclusively 
Table 1. Protein identity list

\begin{tabular}{|c|c|c|c|c|c|c|c|c|c|}
\hline \multirow{2}{*}{$\begin{array}{l}\text { Membrane-associated } \\
\text { proteins }\end{array}$} & \multirow{2}{*}{$\begin{array}{l}\text { Swiss- } \\
\text { Prot } \\
\text { No. }\end{array}$} & \multicolumn{2}{|c|}{$M_{\mathrm{r}}(\mathrm{kDa})$} & \multicolumn{2}{|l|}{$\mathrm{pl}$} & \multirow{2}{*}{$\begin{array}{l}\text { Spot } \\
\text { No. }\end{array}$} & \multirow{2}{*}{$\begin{array}{l}\text { Sequence } \\
\text { coverage } \\
(\%)\end{array}$} & \multirow{2}{*}{$\begin{array}{l}\text { Peptides } \\
\text { matched }\end{array}$} & \multirow{2}{*}{$\begin{array}{l}\text { Labeling } \\
\text { intensity }\end{array}$} \\
\hline & & Gel & Theory & Gel & ory & & & & \\
\hline Lactoferrin & P27788 & 85 & 76.3 & $7.7-8.7$ & 8.5 & 1 & 56 & 40 & + \\
\hline Lactoferrin & P27788 & 80 & 76.3 & $6.3 / 6.5 / 6.7$ & 8.5 & $2 a, b, c$ & $59 / 54 / 33$ & $27 / 26 / 20$ & +++ \\
\hline Lactoferrin & P27788 & 75 & 76.3 & $6.1 / 6.3$ & 8.5 & $3 a, b$ & $7 / 3$ & $5 / 4$ & $+/-$ \\
\hline Lactoferrin & P27788 & 85 & 76.3 & $5.8-6.5$ & 8.5 & $14 a, b$ & $14 / 4$ & $9 / 4$ & - \\
\hline Catalase (bovine) & P00432 & 59 & 57.6 & $6.3-6.4$ & 6.4 & $4 a+b$ & 43 & 19 & +++ \\
\hline Vimentin & P08670 & 57 & 53.6 & 5.0 & 5.1 & 5 & 35 & 19 & ++ \\
\hline Vimentin fragment & P08670 & 56 & 53.6 & 5.1 & 5.1 & 7 & 29 & 12 & + \\
\hline Vimentin fragment & P08670 & 50 & 53.6 & 5.1 & 5.1 & 8 & 12 & 7 & + \\
\hline Vimentin fragment & P08670 & 48 & 53.6 & 5.1 & 5.1 & 9 & 36 & 15 & + \\
\hline Vimentin fragment & P08670 & 40 & 53.6 & 5.1 & 5.1 & 10 & 23 & 9 & + \\
\hline Vimentin (dimer) ${ }^{a)}$ & P08670 & 120 & 53.6 & 6.5 & 5.1 & 15 & 36 & 29 & $+/-$ \\
\hline Filamin $A^{b)}$ & P21333 & 140 & 280 & 4.2 & 5.7 & 6 & 1 & 1 & + \\
\hline$\gamma / \beta$-Actin & P02571 & 42 & 41.7 & 5.2 & 5.3 & 12 & 43 & 14 & - \\
\hline ATP synthase $\beta$-chain & P06576 & 50 & 51.8 & 5.1 & 5.0 & 11 & 30 & 12 & + \\
\hline ATP synthase $\beta$-chain & P06576 & 44 & 51.8 & 6.3 & 5.0 & 18 & 16 & 7 & $+/-$ \\
\hline Myeloperoxidase ${ }^{\mathrm{c})}$ & P05164 & 54 & 53.8 & $9-9.5$ & 9.4 & 13 & 38 & 8 & - \\
\hline Annexin 1 & P04083 & 37 & 38.6 & 6.2 & 6.6 & 17 & 30 & 8 & $+/-$ \\
\hline Cytokeratin 10 (dimer) & P13645 & 95 & 59.5 & 6.5 & 5.1 & 16 & 27 & 26 & - \\
\hline Cytokeratin 10 & P13645 & 44 & 59.5 & 6.4 & 5.1 & 19 & 26 & 24 & + \\
\hline \multicolumn{10}{|l|}{ Soluble proteins } \\
\hline Lactoferrin & P27788 & 85 & 76.3 & $7.7-8.9$ & 8.5 & 1 & 33 & 17 & ++ \\
\hline Catalase (human) & P04040 & 62 & 59.6 & $6.6-6.7$ & 7.0 & 20 & 58 & 27 & - \\
\hline Catalase (bovin) ${ }^{d}$ ) & P00432 & 59 & 57.6 & $6.3-6.4$ & 6.4 & 4 & & & +++ \\
\hline$\alpha$-enolase & P06733 & 45 & 47 & $6.3-6.7$ & 7.0 & $21 a+b$ & 75 & 30 & + \\
\hline $\begin{array}{l}\text { Glyceraldehyde } \\
\text { 3-phosphate } \\
\text { dehydrogenase }\end{array}$ & P04406 & 37 & 35.9 & 9.2 & 8.6 & 22 & 44 & 15 & ++ \\
\hline
\end{tabular}

a) Phosphorylated at Thr-425

b) Half the molecular mass suggesting a monomer

c) $N$-Terminus missing (184 amino acids)

d) Identified by matching with membrane-associated protein map; spot 4 is absent from cells not treated with bovine catalase.

present in the membrane-associated protein map (spot 14, Fig. 3a); the $\mathrm{pl}$ and $M_{\mathrm{r}}$ of this isoform differed from what was reported in the database.

Since the focus of our study was on the oxygen radicalinduced tyrosylation reaction, the pattern of tyrosylated proteins of activated neutrophils was assessed by highresolution 2-D PAGE followed by Western blotting using an anti-fluorescein antibody (Figs. 3c-f). In order to identify the tyrosylated proteins these blots were matched with silver-stained protein maps run in parallel. To assure accurate matching and identification the conditions of 2D PAGE (i.e., pH range, gel size, and acrylamide concentration) were adjusted in case the resolution of the protein of interest was not optimal. A total of 19 proteins were identified by mass spectrometric analysis, which coincided with tyrosylated proteins (for details see Table 1).
Due to low expression and insufficient resolution some tyrosylated proteins were clearly visible on the blots (see Figs. 3c-f) but could not be identified by MS.

\subsection{Identification of tyrosylated proteins after PMA activation}

Immunoblot analysis showed that seven membraneassociated proteins (spots 1-6, 15) were clearly tyrosylated of which proteins 2 and 4 most heavily (Fig. 3c). In the case of soluble proteins two proteins (spots 1,4) were clearly and two proteins (spots 21,22 ) slightly labeled (Fig. 3d). Spot 1 (Figs. 3c, d) was identified as lactoferrin $(85 \mathrm{kDa}, \mathrm{p} / 7.9-8.7)$. This protein is prominently present in both the membrane-associated and soluble protein fractions (Figs. 3a, b). In nonstimulated cells this basic iso- 
form is exclusively present in the soluble fraction (data not shown) suggesting that after PMA-activation this protein is translocated to the plasma membrane. A chain of seven spots represented an $80 \mathrm{kDa}$ membrane-associated protein that was most susceptible to undergo tyrosylation (spot 2, Fig. 3c). Four of these spots (spots 2a-d; Fig. 3a) were analyzed separately and each identified as lactoferrin. It is to be noted that this neutral lactoferrin isoform $(\mathrm{p} /$ range 6.2-7.4) does not occur in the soluble fraction. Two additional membrane-associated neutral lactoferrin isoforms were identified; one of $75 \mathrm{kDa}$ (spots 3a,b,c; Fig. 3a) and one of $85 \mathrm{kDa}$ (spots 14a,b,c; Fig. 3a); only the $75 \mathrm{kDa}$ form was tyrosylated (spot 3, Fig. 3c). The heavily tyrosylated protein (spot 4, Figs. 3c, d) was identified as bovine catalase, which was added to activated neutrophils to abolish further tyrosyl radical formation. It is to be noted that the highly expressed endogenous catalase (protein 20 , Fig. 3b) was not tyrosylated. Bovine catalase was detected both in the membrane-associated (spots 4a,b, Fig. 3a) and soluble protein fraction (spot 4, Fig. 3b).

Spots 5 and 6 (Fig. 3c) were identified as vimentin and filamin A. This indicates that during neutrophil activation these cytoskeletal proteins become tyrosylated possibly as a result of their being associated with the plasma membrane [30]. Spot 15 (Fig. 3a and Fig. 4, lower panel, insert) was identified as vimentin at double the molecular mass (120 kDa). Given the high sequence coverage (36\%) and the exclusive detection of vimentin peptides (a total of 29) we infer that this slightly tyrosylated protein represents the vimentin dimer. Extensive LC-MS/MS analysis of the peptides obtained from the vimentin dimer yielded one peptide (see middle panel) that was phosphorylated at Thr-425 (upper panel, Fig. 4).

As for the soluble protein fraction (Fig. 3d), two enzymes of the glycolytic pathway were found to be tyrosylated, i.e., $\alpha$-enolase (spot 21) and glyceraldehyde 3-phosphate dehydrogenase (spot 22). $\alpha$-Enolase is expressed on the surface of neutrophils and acts as a plasminogen receptor [31]. Glyceraldehyde 3-phosphate dehydrogenase is prominently present in the plasma membrane of erythrocytes [32] and retinal photoreceptor outer segments [33] and in the synaptic plasma membranes from brain [34]. It has been demonstrated that oxygen radicals can induce the reversible membrane-cytoplasm translocation of glyceraldehyde 3-phosphate dehydrogenase in human erythrocytes [35].

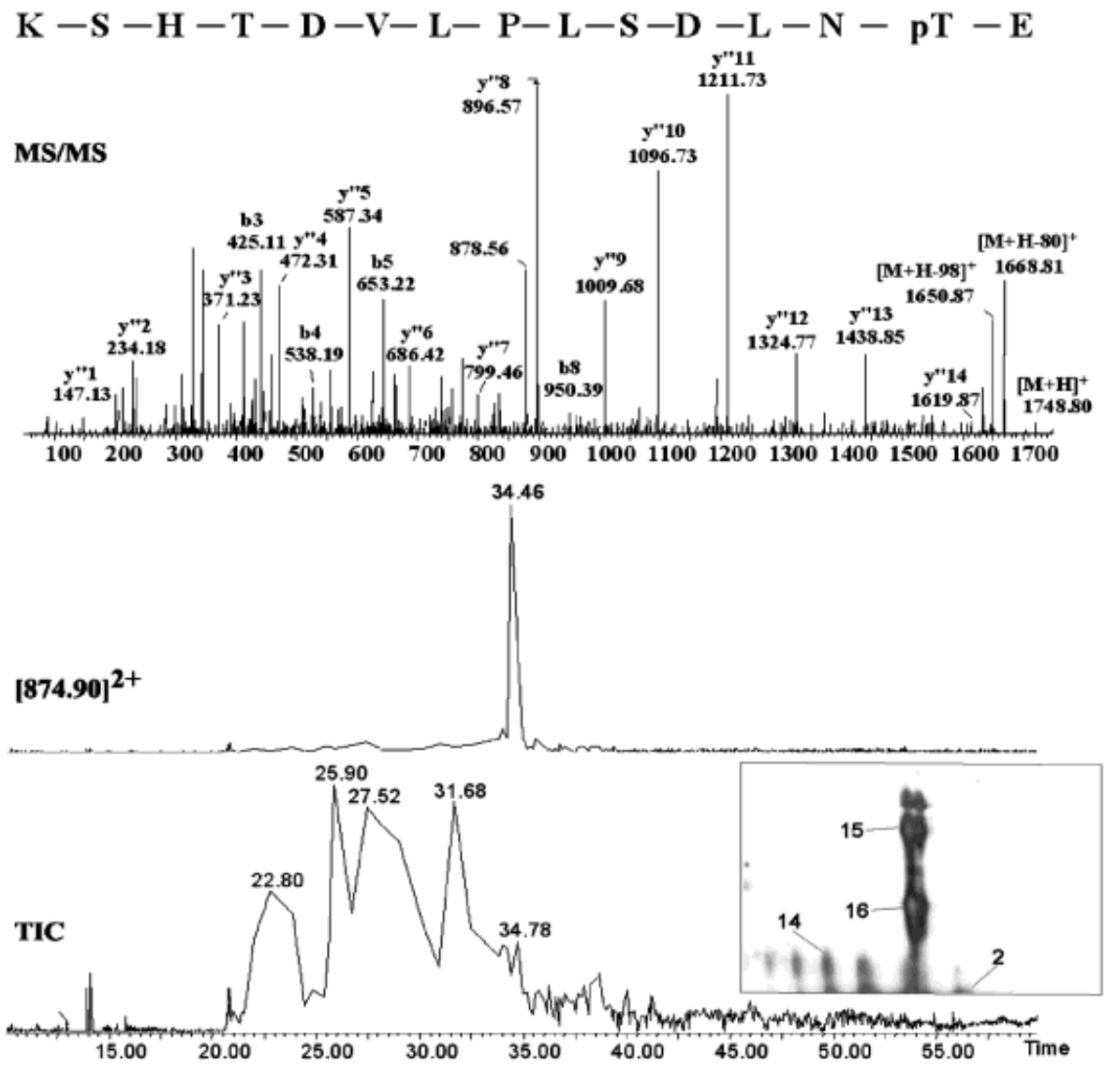

(C) 2004 WILEY-VCH Verlag GmbH \& Co. KGaA, Weinheim
Figure 4. Identification of the phosphorylation site in vimentin dimer $(120 \mathrm{kDa})$. In the lower panel a LC-MS total ion chromatogram (TIC) of all the tryptic peptides of vimentin dimer (spot 15; see insert, obtained from a 2-D gel using a $17 \mathrm{~cm}$ IPG strip, $\mathrm{pH}$ 3-10). In the middle panel the chromatographic resolution as presented by the extracted mass chromatogram of the tryptic vimentin peptide predicted to be phosphorylated (ETNLDSL PLVDTHSK + $80 \mathrm{Da})$. In the top panel the MS/MS spectrum of this peptide shows a clear y"ion series from which is concluded that Thr-425 is phosphorylated.

www.proteomics-journal.de 


\subsection{Identification of tyrosylated proteins after IFN- $\gamma$ and TNF- $\alpha$ activation}

Given the formation of extracellular dityrosine after activation by IFN- $\gamma$ and TNF- $\alpha$ (Fig. 1) we assessed whether these cytokines can induce protein tyrosylation. As shown in Fig. 3e, IFN- $\gamma$ gave rise to tyrosylation of basic and neutral lactoferrin (spots 1-3), bovine catalase (spot 4), and a very distinct tyrosylation of vimentin (spot 5 ), ATP synthase $\beta$ (spots 11, 18), annexin I (spot 17), and cytokeratin 10 (spot 19). Moreover, tyrosylated vimentin fragments (spots 7-10) were identified. ATP synthase $\beta$ is present at the cell surface of lymphocytes [36] and endothelial cells [37].

TNF- $\alpha$ gave a comparable protein tyrosylation pattern, yet particularly, the tyrosylation of the $80 \mathrm{kDa}$ neutral lactoferrin appeared to be less pronounced whilst spots 17-19 were not visible (Fig. 3f). As one can see from the protein map (Fig. 3a) some of the vimentin fragments (spots 7-9) were poorly resolved. To ensure an accurate identification and matching with the Western blots, the resolution of these fragments was greatly enhanced by carrying out 2D PAGE in a pH range of 4-7 (data not shown). Spots were excised from 2-3 gels run in parallel. Analyses of the soluble protein fractions indicated that activation by TNF- $\alpha$ gave a protein tyrosylation pattern identical to that of PMA (Fig. 3d).

\section{Discussion}

In the present study we have shown that activated neutrophils tyrosylate a limited number of endogenous proteins as a result of extracellular tyrosyl radical formation. These tyrosylated proteins were identified by a combination of Western blotting and proteomic analysis. Initially we followed the time course of extracellular tyrosyl radical generation by measuring the formation of the dityrosine analogue dityramine. Dityramine formation after PMA activation was very rapid reflecting the direct activation of PKC and as a consequence the almost instantaneous generation of the oxidative burst. Very interestingly we found that activation by TNF- $\alpha$ and IFN- $\gamma$ also induced dityramine formation, yet after a delay of 15-20 min. This delay most likely reflects another pathway of radical generation as a result of cytokine receptor activation. In a previous study, $\mathrm{H}_{2} \mathrm{O}_{2}$ release by neutrophils was observed 1590 min after TNF- $\alpha$ or IFN- $\gamma$ activation [38]. This delay was thought to reflect the assembly of microfilaments. Whereas dityramine formation after PMA activation reached a plateau after about $30 \mathrm{~min}$, we observed that activation by IFN- $\gamma$ induced tyrosyl radical generation for up to $2 \mathrm{~h}$ (data not shown). Consistent with this, IFN- $\gamma$ has been demonstrated to significantly increase the expression of a gene encoding for gp9 $1^{\text {phox }}$, one of the components of the NADPH complex after $1 \mathrm{~h}$ with a maximum between 2 and $4 \mathrm{~h}$ [39]. Zymosan activation of mouse phagocytes deficient in gp91 ${ }^{\text {phox }}$ failed to produce protein-bound o,o'-dityrosine [18].

In agreement with dityramine formation we observed that in the presence of TyrFluo neutrophil proteins became labeled after PMA and cytokine activation. This labeling indicates that during the oxidative burst TyrFluo is converted into the tyrosyl radical before it is able to couple to oxidized tyrosine residues in proteins. Given the nature of the coupling reaction we have evidence that the TyrFluo radicals tend to dimerize as a result of which the coupling of the probe to the protein is low. In other words, only a small percentage of the oxidized protein is actually coupled to the probe. This explains why mass spectrometric analysis of the labeled proteins failed to provide direct evidence for the formation of dityrosine bonds between TyrFluo and the target proteins. However, mass spectrometric analysis of peptides submitted to radical-induced oxidation indicated that TyrFluo coupled exclusively to tyrosine residues by formation of dityrosine bonds (manuscript in preparation). Since the membrane-permeable probe acetylTyrFluo did not label any proteins we infer that during the oxidative burst tyrosyl radicals are formed only extracellularly. This implies that the attack by tyrosyl radicals is restricted to proteins exposed to the medium. This was confirmed by confocal microscopy showing that the fluorescently labeled proteins were predominantly located in patches on the cell surface. After the initial labeling we found that the oxidatively modified (tyrosylated) proteins were internalized most likely to be degraded.

One of the major tyrosylated proteins identified was a neutral isoform of lactoferrin $\left(M_{\mathrm{r}} 80 \mathrm{kDa}, \mathrm{p} / 6.2-7.4\right)$. This glycoprotein isoform was exclusively present in the map of membrane-associated proteins and comprised a chain of seven spots, which may reflect different degrees of glycosylation. In addition, two other membrane-associated neutral isoforms $\left(M_{\mathrm{r}} 75 \mathrm{kDa}\right.$ and $\left.85 \mathrm{kDa}\right)$ were identified of which the $75 \mathrm{kDa}$ form was slightly tyrosylated. Upon neutrophil activation the basic isoform of lactoferrin $\left(M_{\mathrm{r}}\right.$ $85 \mathrm{kDa}, \mathrm{pl} 7.9-8.7$ ), which is a soluble protein, is found in the membrane-associated fraction in a tyrosylated form. Given that activation triggers the secretion of the basic lactoferrin [40] the tyrosylation reaction may have occurred in the medium. Binding to lactoferrin receptors may explain why the tyrosylated form also occurs in the soluble fraction [41]. In agreement with our findings it was recently shown that three lactoferrin isoforms of 75 , 80 , and $85 \mathrm{kDa}$ were constitutively expressed in the plasma membrane and secondary granules of resting neutrophils [42]. 
Another major tyrosylated protein present both in the membrane and soluble fraction was bovine catalase. This enzyme is commonly used to abolish the formation of tyrosyl radicals [10]. It is known that catalase in the process of decomposing $\mathrm{H}_{2} \mathrm{O}_{2}$ forms endogenous tyrosyl radicals [43]. It could be that these radicals are involved in cross-linking TyrFluo tyrosyl radicals to the catalase itself. It remains to be established whether the recovery of bovine catalase from the cells reflects an actual internalization. Other heme proteins have been found to be internalized into neutrophils (oxyhemoglobin) [44] or transcytosed into the intact endothelium (MPO) [45].

In activated neutrophils vimentin and filamin A were found to be tyrosylated. The susceptibility of these two structural proteins to tyrosyl radical attack may be explained by their binding to several cellular proteins, including membrane receptors and intracellular signaling molecules [30]. By becoming associated with $\beta$-integrin receptors, which are translocated from granulocytic or vesicular stores to the plasma membrane upon cell stimulation vimentin and filamin A can facilitate the activation of local cellular processes [46]. Tyrosylation of vimentin was particularly pronounced after cytokine stimulation. This may be explained by the recent observation that TNF- $\alpha$ may trigger vimentin secretion in the extracellular space of stimulated human monocytes [47]. As indicated, secreted vimentin is phosphorylated at serine and threonine residues and acts as an anti-bacterial protein. In the membrane-associated protein maps we have found vimentin as a monomer (spot 5) and also as a dimer (spot 15). In fact, it appears that vimentin is predominantly present in the dimer form, yet in contrast to the monomer the dimer form is only slightly tyrosylated. The formation of the vimentin dimer only occurs in activated cells (data not shown). Our finding that a carboxy-terminal peptide of vimentin was phosphorylated at Thr-425 may be a prerequisite for its translocation to the plasma membrane. We identified cytokeratin 10 as another member of the intermediate filaments in neutrophils. This protein was found as a tyosylated monomer (spot 19), and also occurred as a dimer (spot 16). We only observed tyrosylated vimentin fragments under conditions of cytokine activation. These fragments may be formed by caspases known to be activated by pro-inflammatory cytokines [48, 49]. Similar vimentin fragments were also detected in human macrophages undergoing apoptosis induced by oxidized lowdensity lipoproteins (LDLs) [50].

As regards the neutrophil proteome, we have made a soluble and a membrane-associated protein map so as to enhance the resolution and to enable us to distinguish the localization of specific proteins. By this proteomics approach we have identified for the first time in human neutrophils different isoforms of lactoferrin and myeloper- oxidase two essential proteins involved in pathogen clearance and hallmark components of neutrophil phagolysosomal structures. These two proteins could be used as proteomic markers for the differentiation of myeloid stem cells and promyelocytic HL-60 cells to mature granulocyte-like cells. Another protein identified was filamin A, one of the structural proteins connected to plasma membrane glycoproteins. It is of great interest that some of the proteins involved in energy metabolism (i.e., ATP synthase $\beta, \alpha$-enolase, and glyceraldehyde 3 -phosphate dehydrogenase) could also be tyrosylated. These proteins have also been identified in the phagolysosome proteome of macrophages [51].

By use of proteome analysis in combination with the tyrosylating agent TyrFluo we have demonstrated for the first time that in activated neutrophils lactoferrin and vimentin are the proteins most susceptible to tyrosyl radical attack. It is to be noted that these proteins are involved in bacterial killing. It remains to be established to what extent the tyrosylation reaction affects the bactericidal function of these proteins.

This work was supported with a grant of the Council for Chemical Sciences of the Netherlands Organization for Scientific Research (NWO-CW). We thank C. M. van Tiel for help with preparing the figures, T. Dansen for making the confocal images, J. Westerman for technical assistance, and C. de Haas, J. van Strijp, L. Koenderman and E. Fortunati (University Medical Center, Utrecht University) and E. van Anken (Bijvoet Institute, Utrecht University) for helpful discussions.

\section{References}

[1] Fridovich, I., J. Biol. Chem. 1997, 272, 18515-18517.

[2] Dean, R. T., Fu, S., Stocker, R., Davies, M. J., Biochem. J. 1997, 324, 1-18.

[3] Stanbro, W. D., J. Theor. Biol. 1998, 193, 59-68.

[4] Britigan, B. E., Rosen, G. M., Thompson, B. Y., Chai, Y. et al., J. Biol. Chem. 1986, 261, 17026-17032.

[5] MacMillan-Crow, L. A., Crow, J. P., Thompson, J. A., Biochemistry 1998, 37, 1613-1622.

[6] Eiserich, J. P., Patel, R. P., O'Donnell, V. B., Mol. Aspects Med. 1998, 19, 221-357.

[7] van der Vliet, A., Hristova, M., Cross, C. E., Eiserich, J. P. et al., J. Biol. Chem. 1998, 273, 31860-31866.

[8] Heinecke, J. W., Li, W., Daehnke III, H. L., Goldstein, J. A., J. Biol. Chem. 1993, 268, 4069-4077.

[9] Marquez, L. A., Dunford, H. B., J. Biol. Chem. 1995, 270, 30434-30440.

[10] Jacob, J. S., Cistola, D. P., Hsu, F. F., Muzaffar, S. et al., J. Biol. Chem. 1996, 271, 19950-19956.

[11] Hazen, S. L., Heinecke, J. W., J. Clin. Invest. 1997, 99, 20752081.

[12] Kettle, A. J., FEBS Lett. 1996, 379, 103-106. 
[13] Pfeiffer, S., Schmidt, K., Mayer, B., J. Biol. Chem. 2000, 275 6346-6352.

[14] Heinecke, J. W., Toxicology 2002, 177, 11-22.

[15] Heinecke, J. W., FASEB J. 1999, 13, 1113-1120.

[16] Czapski, G. A., Avram, D., Sakharov, D. V., Wirtz, K. W. et al., Biochem. J. 2002, 365, 897-902.

[17] Larios, J. M., Budhiraja, R., Fanburg, B. L., Thannickal, V. J., J. Biol. Chem. 2001, 276, 17437-17441.

[18] Bhattacharjee, S., Pennathur, S., Byun, J., Crowley, J. et al., Arch. Biochem. Biophys. 2001, 395, 69-77.

[19] Jasin, H. E., J. Immunol. 1983, 130, 1918-1923.

[20] van der Vlies, D., Wirtz, K. W., Pap, E. H., Biochemistry 2001, 40, 7783-7788.

[21] Molloy, M. P., Herbert, B. R., Walsh, B. J., Tyler, M. I. et al., Electrophoresis 1998, 19, 837-844.

[22] Celis, J. E., R., G., Basse, B., Lauridsen, J. B., Celis, A., Jensen, N. A., Gromov, P., High-resolution two-dimensional electrophoresis of proteins: Isoelectric focusing (IEF) and nonequilibrium $\mathrm{pH}$ gradients electrophoresis (NEPHGE). Vol. 4, Academic Press San Diego, CA 1998.

[23] Wilm, M., Shevchenko, A., Houthaeve, T., Breit, S. et al., Nature 1996, 379, 466-469.

[24] van Anken, E., Romijn, E. P., Maggioni, C., Mezghrani, A. et al., Immunity 2003, 18, 243-253.

[25] Meiring, H. D., van der Heeft, E., ten Hove, G. J., de Jong, A., J. Sep. Sci. 2002, 25, 557-568.

[26] Perkins, D. N., Pappin, D. J., Creasy, D. M., Cottrell, J. S., Electrophoresis 1999, 20, 3551-3567.

[27] Dri, P., Haas, E., Cramer, R., Menegazzi, R. et al., J. Immunol. 1999, 162, 460-466.

[28] Lundqvist-Gustafsson, H., Bengtsson, T., J. Leukoc. Biol. 1999, 65, 196-204.

[29] Bass, D. A., Parce, J. W., Dechatelet, L. R., Szejda, P. et al., J. Immunol. 1983, 130, 1910-1917.

[30] Stossel, T. P., Condeelis, J., Cooley, L., Hartwig, J. H. et al., Nat. Rev. Mol. Cell. Biol. 2001, 2, 138-145.

[31] Redlitz, A., Fowler, B. J., Plow, E. F., Miles, L. A., Eur. J. Biochem. 1995, 227, 407-415.
[32] Rogalski, A. A., Steck, T. L., Waseem, A., J. Biol. Chem. 1989, 264, 6438-6446.

[33] Hsu, S. C., Molday, R. S., J. Biol. Chem. 1990, 265, 1330813313.

[34] Bulliard, C., Zurbriggen, R., Tornare, J., Faty, M. et al., Biochem. J. 1997, 324, 555-563.

[35] Mallozzi, C., Di Stasi, A. M., Minetti, M., Arch. Biochem. Biophys. 1995, 321, 345-352.

[36] Das, B., Mondragon, M. O., Sadeghian, M., Hatcher, V. B. et al., J. Exp. Med. 1994, 180, 273-281.

[37] Moser, T. L., Kenan, D. J., Ashley, T. A., Roy, J. A. et al., Proc. Natl. Acad Sci. USA 2001, 98, 6656-6661.

[38] Nathan, C. F., J. Clin. Invest. 1987, 80, 1550-1560.

[39] Cassatella, M. A., Bazzoni, F., Flynn, R. M., Dusi, S. et al., J. Biol. Chem. 1990, 265, 20241-20246.

[40] Boussac, M., Garin, J., Electrophoresis 2000, 21, 665-672.

[41] Suzuki, Y. A., Shin, K., Lonnerdal, B., Biochemistry 2001, 40, 15771-15779.

[42] Deriy, L. V., Chor, J., Thomas, L. L., Biochem. Biophys. Res. Commun. 2000, 275, 241-246.

[43] Putnam, C. D., Arvai, A. S., Bourne, Y., Tainer, J. A., J. Mol. Biol. 2000, 296, 295-309.

[44] Cassidy, R. A., Burleson, D. G., Delgado, A. V., Kohler, D. J. et al., J. Leukoc. Biol. 2000, 67, 357-368.

[45] Baldus, S., Eiserich, J. P., Mani, A., Castro, L. et al., J. Clin. Invest. 2001, 108, 1759-1770.

[46] Borregaard, N., Cowland, J. B., Blood 1997, 89, 3503-3521.

[47] Mor-Vaknin, N., Punturieri, A., Sitwala, K., Markovitz, D. M., Nat. Cell. Biol. 2003, 5, 59-63.

[48] Fulda, S., Debatin, K. M., Oncogene 2002, 21, 2295-2308.

[49] Suk, K., Chang, I., Kim, Y. H., Kim, S. et al., J. Biol. Chem. 2001, 276, 13153-13159.

[50] Muller, K., Dulku, S., Hardwick, S. J., Skepper, J. N. et al., Atherosclerosis 2001, 156, 133-144.

[51] Garin, J., Diez, R., Kieffer, S., Dermine, J. F. et al., J. Cell. Biol. 2001, 152, 165-180. 